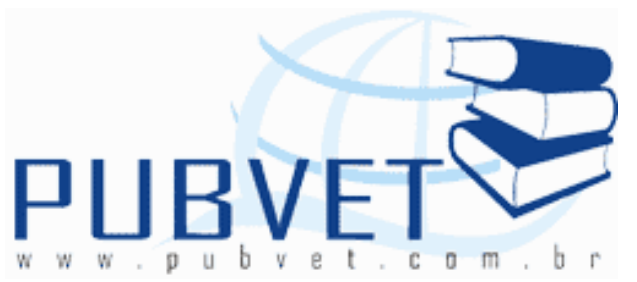

PUBVET, Publicações em Medicina Veterinária e Zootecnia.

\title{
Propriedades químicas e rendimento da piramutaba (Brachyplastystoma vaillantii, Valenciennes, 1840)
}

\author{
Pedro Roberto de Oliveira ${ }^{1}$ José Maria B. Damasceno ${ }^{2}$
}

1 Universidade Federal do Amazonas - Faculdade de Ciências Agrárias/Departamento de Ciências Pesqueiras, Av. Rodrigo Otávio, 3000 Aleixo CEP: 69077-000 - Manaus, AM - Brasil, e-mail: poliveira@ufam.edu.br

${ }^{2}$ Engenheiro de Pesca - Secretaria de Desenvolvimento Sustentável, Município de Fonte Boa, Amazonas

\section{Resumo}

A piramutaba é matéria prima para a indústria pesqueira onde é destinada ao beneficiamento na forma de filé congelado. O presente estudo foi realizado com o objetivo de verificar a determinação do rendimento na indústria e determinar a composição centesimal do filé e do resíduo. Para avaliar a composição centesimal do filé e do resíduo foram adquiridos 20 exemplares, junto aos barcos de pesca, com peso médio de 1093,50 g. Os dados de rendimentos foram calculados na linha de produção das industrias, e tomadas como amostras 15 lotes ao longo da produção. Os resultados obtidos mostraram que os rendimentos médios, partindo de amostras evisceradas, foram de 33,3 6\% para filé sem pele, 23,30 \% para cabeça e 43,34\% resíduo. A análise da composição centesimal para o filé mostrou valores de $78,03 \%$ de umidade; $15,72 \%$ de proteína; $5,83 \%$ de lipídeo e 0,74 \% de 
OLIVEIRA, P.R. e DAMASCENO, J.M.B. Propriedades químicas e rendimento da piramutaba (Brachyplastystoma vaillantii, Valenciennes, 1840). PUBVET, Londrina, V. 8, N. 14, Ed. 263, Art. 1750, Julho, 2014.

cinza. Já para os resíduo observou-se $70,33 \%$ de umidade; $14,32 \%$ de proteína; $10,76 \%$ de lipídeo; $1,54 \%$ de cinza. Com base nos dados obtidos pode-se concluir que a piramutaba é uma espécies com alto teor lipídico, e apresenta rendimento médio dentro dos valores normalmente encontrado para peixes comerciais.

Palavras-chave: piramutaba, proteína, indústria pesqueira.

\title{
Chemical composition and yield of piramutaba (Brachyplastystoma vaillantii, Valenciennes, 1840)
}

\begin{abstract}
The piramutaba is specie processed and sold in the refrigerated frozen fillet. The present study was conducted to determine in the industry the yield and chemical composition of the fillet and the residue. About 20 samples were collected for the determination of the chemical composition of the fillet and the residue, average weight $1093,50 \mathrm{~g}$. The yield data were calculated on the production line of industry fish, samples from 15 lots of the production line. The results show that the average yields were $33.3 \%$ for fillet without skin, $23.30 \%$ head and $43.34 \%$ for residue. The analysis of the chemical composition on fillet indicated $78.03 \%$ moisture, $15.72 \%$ protein, $5.83 \%$ lipid and $0.74 \%$ ash. Already residue was observed $70.33 \%$ moisture, $14.32 \%$ protein, $10.76 \%$ lipid, $1.54 \%$ ash. Based on the data obtained it can be concluded that the species is a piramutaba with both high fat content in the fillet, especially in the waste, and yield was within the range normally encountered in fish.
\end{abstract}

Keyword: piramutaba, centesimal composition, fishing industry. 
OLIVEIRA, P.R. e DAMASCENO, J.M.B. Propriedades químicas e rendimento da piramutaba (Brachyplastystoma vaillantii, Valenciennes, 1840). PUBVET, Londrina, V. 8, N. 14, Ed. 263, Art. 1750, Julho, 2014.

\section{Introdução}

A piramutaba é um peixe sem escamas também conhecido como bagre, alcança cerca de um metro de comprimento e pesa aproximadamente $10 \mathrm{~kg}$ de peso total. Espécie migradora sobe o rio Amazonas entre os meses de junho e novembro quando é capturada pela frota de água doce (BARTHEM et. al., 1991 e 1992). É explorada industrialmente no Estado do Amazonas e Pará e é nesse Estado onde ocorre a maior parte das capturas (ALMEIDA, 2006).

Segundo Batista e Freitas (2003), o alto desperdício do pescado na região do baixo Solimões, Amazonas, o nível de descarte foi de $20 \%$, dados obtidos nos barcos de pesca no momento do desembarque. E não existem dados sobre o que se tem de resíduos procedente dos frigoríficos.

O resíduo tem seu valor comercial pois pode ser destinado a elaboração de subprodutos de pescado, por exemplo, como material prima destinada a elaboração de farinha de peixe e ensilado. É sabido que os resíduos produzidos como resultado de produtos da linha de produção tem teor protéico relevante, e, se não aproveitado torna-se impróprio para a elaboração de produtos, e é também jogado nos rios e outros locais, levando a médio e longo prazo promover danos ao meio ambiente.

A melhor utilização do resíduo de pescado também pode levar ao aumento na oferta de fonte proteica de boa qualidade. Assim, na indústria, parte da matéria-prima, a que é descartada, poderia ser aproveitada para a elaboração de pastas e de farinha de peixe. Em complemento, o melhor aproveitamento da carne do pescado se dá a partir do conhecimento de sua composição química (HUSS,1998). Como em vários trabalho se tem mostrado a importância quanto a caracterização da matéria-prima com relação a composição e rendimento de carcaça e filé (SANTOS et al., 2000; GOMIERO et al., 2003, BOSCOLO et al, 2004; SOUZA e INHAMUNS, 2011). 
OLIVEIRA, P.R. e DAMASCENO, J.M.B. Propriedades químicas e rendimento da piramutaba (Brachyplastystoma vaillantii, Valenciennes, 1840). PUBVET, Londrina, V. 8, N. 14, Ed. 263, Art. 1750, Julho, 2014.

O nível percentual de filé e resíduo de acordo com Vidotti e Gonçalves (2006), onde citam que a tilápia como exemplo, é de $30 \%$ para o filé e $70 \%$ de resíduos.

O presente estudo teve como objetivo caracterizar a composição centesimal do file e do resíduo de piramutaba e além de conhecer o rendimento em filé, cabeça e resíduos nas linhas de processamento industrial.

\section{Material e Métodos}

\section{Tratamento das amostras}

Para a composição centesimal foram analisados 20 exemplares de piramutaba adquiridos na Feira da Panair, na cidade de Manaus. Os peixes foram acondicionados em caixas de isopor com gelo na proporção 1:1 e transportadas até o Laboratório de Tecnologia de Pescado da Universidade Federal do Amazonas. As amostras apresentaram peso médio de 1093,50 g e comprimento médio de $40 \mathrm{~cm}$.

Para a determinação do rendimento foram realizadas 15 repetições, as amostras constaram dos peixes processados na linha de produção da empresa beneficiadora localizada no município de Iranduba, Amazonas, Brasil.

\section{Composição centesimal}

A preparação das amostras de pescado para análises químicas do músculo e do resíduo, foi realizada da seguinte forma: filés sem pele, triturados em homogeneizador universal, utilizando cinco indivíduos por espécie para as determinações. Dos mesmos exemplares que foi retirado os filés, utilizou-se também os resíduos para análises seguindo os mesmos procedimentos para os filés. A amostra de resíduo não constou a parte da cabeça. As análises foram realizadas baseadas nas Normas Analíticas do 
OLIVEIRA, P.R. e DAMASCENO, J.M.B. Propriedades químicas e rendimento da piramutaba (Brachyplastystoma vaillantii, Valenciennes, 1840). PUBVET, Londrina, V. 8, N. 14, Ed. 263, Art. 1750, Julho, 2014.

Instituto Adolfo Lutz (SÃO PAULO, 1985), obedecendo aos seguintes procedimentos:

Umidade: foi determinada em triplicata com aproximadamente 5 gramas cada uma, em balança analítica eletrônica digital com precisão de 0,0001g, em cadinhos previamente tarados e colocados em estufa a $105^{\circ} \mathrm{C}$ até peso constante.

Proteína: foram determinados através do método Kjeldahl, utilizando-se um bloco digestor e um destilador. As quantidades de proteína bruta nas amostras foram obtidas multiplicando-se o teor de nitrogênio pelo fator 6,25. Foram utilizadas três amostras com aproximadamente 2 gramas cada uma.

Lipídios: foram determinados através da extração contínua com éter etílico, em aparelho de Soxleth por um período de 6 horas. Foram utilizadas três amostras com aproximadamente 5 gramas cada uma.

Cinza: foram determinadas através da carbonização em temperatura baixa e incineração em mufla, a $550^{\circ} \mathrm{C}$ até peso constante. Foram utilizadas três amostras com aproximadamente 3 gramas cada uma.

Rendimento : A determinação do rendimento de filé e resíduo para a piramutaba, processo manual, se deu na linha de produção de uma indústria pesqueira localizadas nos municípios de Iranduba. O pescado foi pesado inteiro de acordo com a espécie, antes de ir para a linha de processamento. Após o seu processamento pesaram-se os filés e os resíduos, determinado também os valores em percentual. O peixes já chegavam nas empresas eviscerados. $O$ tipo de corte na maioria dos casos foi observado o corte reto. No cálculo, utilizou-se a seguinte fórmula: Rendimento $=($ Peso final $/$ Peso inicial $) \times 100$ para cálculo dos percentuais do rendimento de filé sem pele, cabeça e resíduo (coluna, pele, nadadeiras).

\section{Análise estatística}

Os dados obtidos de composição centesimal foram submetidos a analise do teste t-Student ao nível se $5 \%$ de significância para verificar a diferença 
OLIVEIRA, P.R. e DAMASCENO, J.M.B. Propriedades químicas e rendimento da piramutaba (Brachyplastystoma vaillantii, Valenciennes, 1840). PUBVET, Londrina, V. 8, N. 14, Ed. 263, Art. 1750, Julho, 2014.

entre composição química do filé e do resíduo, e estatística descritiva com media, desvio padrão e coeficiente de variação para os valores de rendimento (ZARR, 1999).

\section{Resultados e discussão}

$\mathrm{Na}$ Tabela 01 estão indicados os valores de rendimentos, em kg, e em percentuais calculados com dados obtidos na linha de produção da empresa. As amostras correspondem à produção diária. Foram amostrados 15 lotes da produção cujo peso total dos lotes variou entre 1.500 a 13.700 quilogramas.

Embora os lotes tomados na amostragem tenha variado, evidenciado na observação dos valores expressos pelo coeficiente de variação (CV) entre 45,1 a 43,4 \%. Por outro lado, observa-se que no resultado do rendimento a variação foi pequena tanto para o filé $3,4 \%$, como cabeça $2,1 \%$ e resíduo em $3,1 \%$, significando que embora as repetições (lotes) tenham variado, portanto os valores de rendimento não foram afetados pela variabilidade dos lotes. Também pode-se inferir que essa pouca diferença é provavelmente por causa do processamento ter sido conduzido sempre pelos mesmos funcionários, eliminando-se o efeito do operador.

Souza e Inhamuns (2011) mostram que o rendimento do filé com pele de piramutaba foi de $29,51 \% \pm 4,73$ no período de cheia e $29,54 \% \pm 2,30$ na época da seca dos rios amazônicos. Estes dados, em média, foram menores do que no presente estudo, entretanto, são concordantes se observar o desvio padrão. Estas diferenças podem ser devido a influencia da operação de descabeçamento quanto ao tipo de corte e em relação a classe de peso. Já que estudos realizados por Gomiero et. Al. (2003) mostram que para a matrinchã o corte obliquo foi o mais eficiente do que o corte reto e Luiza e Maranhão (2001) concluíram que o rendimento da tilápia foi influenciado pelas diferentes classes de peso. 
OLIVEIRA, P.R. e DAMASCENO, J.M.B. Propriedades químicas e rendimento da piramutaba (Brachyplastystoma vaillantii, Valenciennes, 1840). PUBVET, Londrina, V. 8, N. 14, Ed. 263, Art. 1750, Julho, 2014.

A composição centesimal do resíduo e do músculo é mostrado na Tabela 02. Observa-se que os valores em percentagem entre proteína bruta do músculo e do resíduo não diferiram estatisticamente a $p<0,05$. Enquanto que umidade, lipídeos e cinza apresentaram diferenças significativas a $p<0,05$, 0 que era de se esperar tendo em vista que nos resíduos há maior concentração de ossos e lipídeos pois parte da região ventral rica em gordura certamente influenciou essa diferença.

Tabela 01 - Valores de rendimento de piramutaba em $\mathrm{kg}$ e percentuais (\%), obtidos na linha de processamento das empresas de pesca.

\begin{tabular}{|c|c|c|c|c|c|c|c|}
\hline \multirow[b]{3}{*}{ Lote } & \multicolumn{7}{|c|}{ Rendimento } \\
\hline & \multicolumn{4}{|c|}{ em kg } & \multicolumn{3}{|c|}{ Em \% } \\
\hline & Inteiro $^{1}$ & $\begin{array}{c}\text { Filé } \\
\text { s/pele }\end{array}$ & Cabeça & Resíduo & $\begin{array}{r}\text { Filé } \\
\text { s/pele }\end{array}$ & Cabeça & Resíduo \\
\hline 1 & 1545,00 & 514,48 & 358,44 & 672,08 & 33,3 & 23,2 & 43,5 \\
\hline 2 & 3458,00 & 1027,03 & 778,05 & 1652,92 & 29,7 & 22,5 & 47,8 \\
\hline 3 & 7674,00 & 2622,21 & 1786,51 & 3265,29 & 34,2 & 23,3 & 42,6 \\
\hline 4 & 5324,00 & 1792,59 & 1227,18 & 2304,23 & 33,7 & 23,0 & 43,3 \\
\hline 5 & 12156,00 & 4130,61 & 2874,89 & 5150,50 & 34,0 & 23,6 & 42,4 \\
\hline 6 & 10623,00 & 3646,88 & 2457,10 & 4519,02 & 34,3 & 23,1 & 42,5 \\
\hline 7 & 6385,00 & 2147,91 & 1533,68 & 2703,41 & 33,6 & 24,0 & 42,3 \\
\hline 8 & 13782,00 & 4688,64 & 3121,62 & 5971,74 & 34,0 & 22,6 & 43,3 \\
\hline 9 & 5436,00 & 1838,46 & 1250,82 & 2346,72 & 33,8 & 23,0 & 43,2 \\
\hline 10 & 9788,00 & 3167,40 & 2249,28 & 4371,32 & 32,4 & 23,0 & 44,7 \\
\hline 11 & 8477,00 & 2844,80 & 2013,29 & 3618,83 & 33,6 & 23,8 & 42,7 \\
\hline 12 & 4673,00 & 1535,08 & 1127,13 & 2010,79 & 32,8 & 24,1 & 43,0 \\
\hline 13 & 10375,00 & 3532,69 & 2374,84 & 4467,48 & 34,1 & 22,9 & 43,1 \\
\hline 14 & 7158,00 & 2370,01 & 1714,34 & 3073,65 & 33,1 & 23,9 & 42,9 \\
\hline 15 & 11328,00 & 3825,47 & 2642,82 & 4859,71 & 33,8 & 23,3 & 42,9 \\
\hline Média & $7.878,80$ & $2.645,62$ & $1.834,00$ & $3.399,18$ & 33,36 & 23,29 & 43,34 \\
\hline $\mathrm{S}^{2}$ & 3464,4 & 1194,4 & 796,8 & 1476,9 & 1,1 & 0,5 & 1,4 \\
\hline $\mathrm{CV}^{2}$ & 44,0 & 45,1 & 43,4 & 43,4 & 3,4 & 2,1 & 3,1 \\
\hline
\end{tabular}

$\overline{1}$ Pescado eviscerado. ${ }^{2}$ desvio padrão (S) e coeficiente de variação (CV) . 
OLIVEIRA, P.R. e DAMASCENO, J.M.B. Propriedades químicas e rendimento da piramutaba (Brachyplastystoma vaillantii, Valenciennes, 1840). PUBVET, Londrina, V. 8, N. 14, Ed. 263, Art. 1750, Julho, 2014.

Quanto a proteína, a diferença entre o filé e o resíduos provavelmente se deu tendo em vista a maior presença da carne da região ventral e entre ossos. E o menor percentual de proteína, como era de se esperar, apresentou valor menor valor para a amostra de resíduo, muito embora não tenha apresentado diferença estatisticamente significante a $\mathrm{p}<0,05$.

A classificação da piramutaba com relação ao teor de lipídeos, diferentemente do encontrada para a traíra por Santos et al. (2000) onde a mesma foi considerada uma espécie magra, com base nesse critério pode-se afirmar que a piramutaba é uma espécie gorda (STANSBY e OLCOTT, 1967).

Tabela 02 - Composição centesimal (\%) do filé e do resíduo de piramutaba

\begin{tabular}{|c|c|c|}
\hline \multirow[b]{2}{*}{ Parâmetro } & \multicolumn{2}{|c|}{ Composição química (\%) } \\
\hline & Filé & Resíduo $^{2}$ \\
\hline Umidade & $78,03 \pm 0,30^{a}$ & $72,33 \pm 0,15^{\mathrm{b}}$ \\
\hline Proteína & $15,72 \pm 0,21^{a}$ & $14,32 \pm 0,33^{a}$ \\
\hline Lipídeo & $5,83 \pm 0,11^{a}$ & $10,76 \pm 0,90^{b}$ \\
\hline Cinza & $0,74 \pm 0,34^{a}$ & $1,54 \pm 0,15^{\mathrm{b}}$ \\
\hline
\end{tabular}


OLIVEIRA, P.R. e DAMASCENO, J.M.B. Propriedades químicas e rendimento da piramutaba (Brachyplastystoma vaillantii, Valenciennes, 1840). PUBVET, Londrina, V. 8, N. 14, Ed. 263, Art. 1750, Julho, 2014.

\section{Conclusão}

De acordo com os dados obtidos, o rendimento calculado na linha de produção foi dentro da faixa de valores esperados para pescado em geral. A composição química entre o resíduo e o filé foram diferentes, principalmente quanto ao teor de lipídeos e a piramutaba pode ser classificada como uma espécie gorda.

\section{Referências}

ALMEIDA, O. T. D. A Industria Pesqueira na Amazônia. Manaus: Ibama/Provárzea. 2006. $110 \mathrm{p}$.

BATISTA, V. S.; FREITAS, V. S. O descarte de pescado na pesca com rede de cerco no baixo rio Solimões, Amazônia Central. Acta Amazônica, 33(1): 127 - 143. 2003.

BARTHEM, R. B, et. al. Life Strategies of Some Long-distance Migratory Catfish in Relation to Hydroelectric Dams in the Amazon Basin. Biological Conservation, 55, p.339-345. 1991.

BARTHEM, R. B. Desenvolvimento da Pesca Comercial na Bacia Amazônica e Consequências para os Estoques Pesqueiros e a Pesca de Subexistência. Documentos Básicos do Encontro de Desenvolvimento Sustentável nos Trópicos Úmidos. Manaus, AM. 13-19/06/92. UNAMAZ.1992

BOSCOLO, W. R., et al. (2004). "Desempenho e características de carcaça de tilápias do Nilo (Oreochromis niloticus L.) alimentadas com rações contendo diferentes níveis de gordura."

Acta Scientiarum Animal Sciences 26(4): 443-447.

BURKERT, D. et al. Rendimentos do processamento e composição química de filés de surubim cultivado em tanques-rede. Revista Brasileira de Zootecnia, Viçosa, v. 37, n. 7, p. 11371143,2008

GOMIERO et al. Rendimento de carcaça de peixe matrinxã (Brycon cephalus) nos diferentes cortes de cabeça. Ciencia Agrotenica, Lavras, v.27, n.1, p211-216, jan/fev., 2003.

HUSS, H. H. El Pescado Fresco: su Calidad y Cambios de su Calidad. FAO, Doc. Técnico de Pesca 348, Roma, Itália. 1998, 202p.

SANTOS et. Al. Composição química e rendimento de filé de traira (Hoplias malabaricus).

Rev.Fac.Zootec. Vet. Agro. V.7, n.1, 33-39p, 2000

SÃO PAULO (Est.) INSTITUTO ADOLFO LUTZ. Normas Analíticas. Vol. I. Métodos Químicos e Físicos para Análises de Alimentos, São Paulo, I Edição Digital, IV edição, p 1020, 2008 
JESUS, R. S. et al. Técnicas para conservação e industrialização de pescado da Amazônia. In: A. L. Val, R. Figliolo and E. Feldberg (ed), Bases Cientificas para a estratégia de Preservação e Desenvolvimento da Amazônia: Fatos e Perspectivas.. Manaus, INPA: p.415 - 439. 1991

SOUZA, A. F. L. Rendimento, composição química e perfil de minerais das principais espécies de peixes comercializadas no Estado do Amazonas. Mestrado (Dissertação). Faculdade de Farmácia, Universidade do Amazonas, Manaus, 2008. 115 p.

SOUZA A. F. L.; e INHAMUNS, A. J. Análise de rendimento cárneo das principais espécies de peixes comercializadas no Estado do Amazonas, Brasil. Acta Amazonica. v.41,n.2, p289-296, 2011

SOUZA, M. L. R.; MARANHÃO, T.C.F. Rendimento de carcaça, filé e subprodutos da filetagem da tilápia do Nilo, Oreochromis niloticus (L), em função do peso corporal Acta Scientiarum, Maringá, v. 23, n. 4, p. 897-901, 2001

STANSBY, M. E.; OLCOTT, H. S. Composición del pescado. In: STANSBY, M. E.; DASSOW, J. A. Tecnologia de la Industria Pesquera. Zaragoza: Acribia, 1967. p. 391-402.

VILA NOVA, C. M. V. M ET AL. Composição química, teor de colesterol e caracterização dos lipídios totais de tilápia (Oreochromis niloticus) e pargo (Lutjanus purpureus), Ciência e Tecnologia de Alimentos, v25, p.430-436, 2005.

VIDOTTI, R. M.; GONÇALVES, G. S. Produção e caracterização de silage, farinha e oleo de tilapia e sua utilização na alimentação animal. disponivel em www.pesca.sp.gov.br, acessado em 30 de outubro de 2006

ZAR, J.H. Biostatistical Analysis. 3a. ed., Prentice Hall, 1996, 662p. 